\title{
Parametric-Based Thermodynamic Analysis of Organic Rankine Cycle as Bottoming Cycle for Combined-Cycle Power Plant
}

\author{
SAMIULLAH QURESHI*, ABDUL GHAFOOR MEMON**, AND ABDUL FATAH ABBASI** \\ RECEIVED ON 12.05.2016 ACCEPTED ON 16.08.2016 \\ ABSTRACT
}

\begin{abstract}
In Pakistan, the thermal efficiency of the power plants is low because of a huge share of fuel energy is dumped into the atmosphere as waste heat. The ORC (Organic Rankine Cycle) has been revealed as one of the promising technologies to recover waste heat to enhance the thermal efficiency of the power plant. In current work, ORC is proposed as a second bottoming cycle for existing CCPP (Combined Cycle Power Plant). In order to assess the efficiency of the plant, a thermodynamic model is developed in the ESS (Engineering Equation Solver) software. The developed model is used for parametric analysis to assess the effects of various operating parameters on the system performance. The analysis of results shows that the integration of ORC system with existing CCPP system enhances the overall power output in the range of 150.5-154.58 MW with 0.24-5\% enhancement in the efficiency depending on the operating conditions. During the parametric analysis of ORC, it is observed that inlet pressure of the turbine shows a significant effect on the performance of the system as compared to other operating parameters.
\end{abstract}

Key Words: Organic Rankine Cycle, Energy Analysis, Combined-Cycle Power Plant.

\section{INTRODUCTION}

$\mathrm{G}$ as turbine power plants play a vital role to convert fossil fuel energy to electricity, although their overall efficiency is not up to the mark and considered to be less efficient. Conventionally, steam turbine cycle is combined with gas turbines to enhance the efficiency and known as CCPP. In Pakistan thermal efficiency of these plants is around $30 \%$ because of aging and poor management [1]. The previously published work has been reviewed for evaluating the effects of different operating parameters on the performance of CCPP. Memon et. al. [2] performed the thermodynamic analysis of simple gas turbine cycle and reported that the net power output and efficiency increased as PR (Pressure Ratio) increases up to a certain value for given CIT (Compressor Inlet Temperature) and GTIT (Gas Turbine Inlet Temperature). Furthermore, Memon, et. al. [3] have concluded through detailed analysis of CCPP that overall power output decreases with a rise in PR while energy efficiency increased with an increment in PR until it reaches 12 for given value of CIT and GTIT. They are also attributed that energy efficiency and overall power output is directly related to GTIT. 
The current study emphases on the techniques to recover the waste heat of CCPP to optimize the thermal efficiency of the plant. This waste heat is a low-grade heat, in order to utilize this waste heat for power generation, some new technologies like the ORC [4], Goswami Cycle [5], Kalina Cycle [6] and trilateral flash cycle [7] were used and analyzed. Due to simple structure, easy maintenance and better capability to convert low grade heat into power [8], ORC has been widely used in different applications like geothermal [9], solar [10], CHP (Combined Heat and Power) [11], waste heat from power plants and industries $[12,13]$. Chacartegui, et. al. [14] studied the ORC as a bottoming cycle for CCPP and found the ORCs as a competitive option to replace conventional Rankine cycle when integrated with high efficient gas turbines. Eveloy, et. al. [15] used the ORC to produce the additional power by utilizing waste heat of gas turbine and achieved 23\% increment in efficiency. Baral, et. al. [16] have analyzed the effect of evaporating pressure on the performance of ORC and reported that thermal efficiency of the system increases with a rise in pressure. Morrone and Algieri [17] have investigated the simple saturated ORC and state that performance of cycle highly sensitive to evaporating temperature. Further, they compared three organic fluids toluene, decane, and cyclohexane. Abadi et. al. [18] have performed thermodynamic analysis of ORC as a bottoming cycle for gas turbine while using fourteen different dry/ wet organic fluids. They concluded that dry fluids are a better choice than wet fluids for ORC as no superheating is required.

In the present study, the exhaust gasses of existing CCPP are utilized to operate simple saturated ORC model in EES software, and the parametric energy analysis has been performed. For this study, the R245fa is selected as working fluid for ORC due to its inflammability, non- toxic nature, low GWP and ODP $[19,20]$. The ORC OTIP (Turbine Inlet Pressure), the gas turbine exhaust gas fraction $(\psi)$, ORC $\mathrm{PPD}_{\text {ORD }}$ (Pitch Point Difference) and ORC ADP ${ }_{\text {ORC }}$
(Approach Point Difference) are taken as operating parameters. While enhancement of power output $\left(\mathrm{W}_{\text {ORC,net }}\right)$, an increase in overall power output $\left(\mathrm{W}_{\text {overall }}\right)$, EnE (Energy Efficiency) and exhaust gas temperature $\left(\mathrm{T}_{\mathrm{EX}}\right)$ are nominated as performance parameters.

\section{PLANT DESCRIPTION}

In the current study, ORC is proposed as a second bottoming cycle for existing CCPP to generate additional power from exhaust gasses. Fig. 1 demonstrates the schematic diagram of the modified system. The CCPP system is adopted from gas turbine power station situated in Kotri, Pakistan. The total power capacity of the plant is $144 \mathrm{MW}$, include the four GT units of $25 \mathrm{MW}$ each combined with 44MW steam turbine via four HRSG (Heat Recovery Steam Generators).

The ORC comprises of HRVG (Heat Recovery Vapor Generator), turbine; a condenser (CND2) and FP (Feed Pump). In the proposed research work, the fraction of GT exhaust gasses $(\psi)$ has been passed directly through HRVG after mixing with remaining GT exhaust coming from HRSG at state 23. As the exhaust gasses passes through HRVG, heat is transferred to the ORC working fluid, and it is heated to saturated vapor condition at state 28 . The working fluid is expanded in the turbine and leaves at state 29 as low pressure superheated vapors. Then, it is condensed while passing through the CND2 and pumped to evaporator pressure at state 26 .

\section{THERMODYNAMIC MODELING AND ASSUMPTIONS}

The thermodynamic model equation for each equipment is developed by applying flowing equations.

Continuity Equation:

$\sum \dot{\mathrm{m}}_{\mathrm{in}}=\sum \dot{\mathrm{m}}_{\text {out }}$ 
Energy Equation:

$\dot{\mathrm{Q}}_{\text {in }}=\dot{\mathrm{W}}_{\text {in }} \sum \dot{\mathrm{m}}_{\text {in }} \mathrm{h}_{\text {in }}=\dot{\mathrm{Q}}_{\text {out }}+\dot{\mathrm{W}}_{\text {out }}+\sum \dot{\mathrm{m}}_{\text {out }} \mathrm{h}_{\text {out }}$

Further, the chemical equation for combustion of $\mathrm{CH}_{4}$, used as fuel in plant, is given as:

$\mathrm{CH}_{4}+\lambda\left(0.7748 \mathrm{~N}_{2}+0.2059 \mathrm{O}_{2}+0.0003 \mathrm{CO}_{2}+0.019 \mathrm{H}_{2} \mathrm{O}\right)$

$\rightarrow(1-\lambda)\left(\alpha_{\mathrm{N}_{2}} \mathrm{~N}_{2}+\alpha_{\mathrm{O}_{2}} \mathrm{O}_{2}+\alpha_{\mathrm{CO}_{2}} \mathrm{CO}_{2}+\mathrm{a}_{\mathrm{H}_{2} \mathrm{O}} \mathrm{H}_{2} \mathrm{O}\right)$

$\alpha_{\mathrm{N}_{2}}=\frac{0.7748 \lambda}{1+\lambda}, \alpha_{\mathrm{O}_{2}}=\frac{0.2059 \lambda-2}{1+\lambda}, \alpha_{\mathrm{CO}_{2}}=\frac{1+0.0003 \lambda}{1+\lambda}, \alpha_{\mathrm{H}_{2} \mathrm{O}}=\frac{2+0.19 \lambda}{1+\lambda}$

The mass fraction of each element is calculated as:

$\beta_{\mathrm{i}}=\frac{\alpha_{\mathrm{i}} \mathrm{M}_{\mathrm{i}}}{\mathrm{M}_{\mathrm{g}}}=\frac{\alpha_{\mathrm{i}} \mathrm{M}_{\mathrm{i}}}{\sum_{\mathrm{i}} \alpha_{\mathrm{i}} \mathrm{M}_{\mathrm{i}}}$

While the mass flow rates of fuel and combustion gasses are given by:

$\dot{\mathrm{m}}_{\mathrm{f}}=\left(\frac{\mathrm{M}_{\mathrm{f}}}{\lambda \mathrm{M}_{\mathrm{air}}}\right) \dot{\mathrm{m}}_{\text {air }}$

$$
\dot{\mathrm{m}}_{\mathrm{g}}=\dot{\mathrm{m}}_{\mathrm{air}}+\dot{\mathrm{m}}_{\mathrm{f}}
$$

The overall power output of modified CCPP is given by:

$\dot{\mathrm{W}}_{\text {overall }}=\dot{\mathrm{W}}_{\mathrm{CCPP}}+\dot{\mathrm{W}}_{\text {orc,net }}$

Where

$\dot{\mathrm{W}}_{\mathrm{CCPP}}=4 \times\left(\dot{\mathrm{W}}_{\mathrm{GT}}-\dot{\mathrm{W}}_{\mathrm{AC}}\right)+\left(\dot{\mathrm{W}}_{\mathrm{ST}}-\dot{\mathrm{W}}_{\mathrm{CP}}-\dot{\mathrm{W}}_{\mathrm{FWP}}\right)$

$\dot{\mathrm{W}}_{\text {orc }, \text { net }}=\dot{\mathrm{W}}_{\text {orc }}-\dot{\mathrm{W}}_{\mathrm{FP}}$

While the efficiencies of ORC and modified CCPP are calculated as:

$\mathrm{EnE}_{\text {orc }}=\frac{\dot{\mathrm{W}}_{\text {orc,net }}}{4 \times \dot{\mathrm{m}}_{\mathrm{g}}\left(\mathrm{h}_{23}-\mathrm{h}_{25}\right)}$

EnE $_{\text {overall }}=\frac{\dot{\mathrm{W}}_{\text {overall }}}{\dot{\mathrm{Q}}_{\text {in }}}$

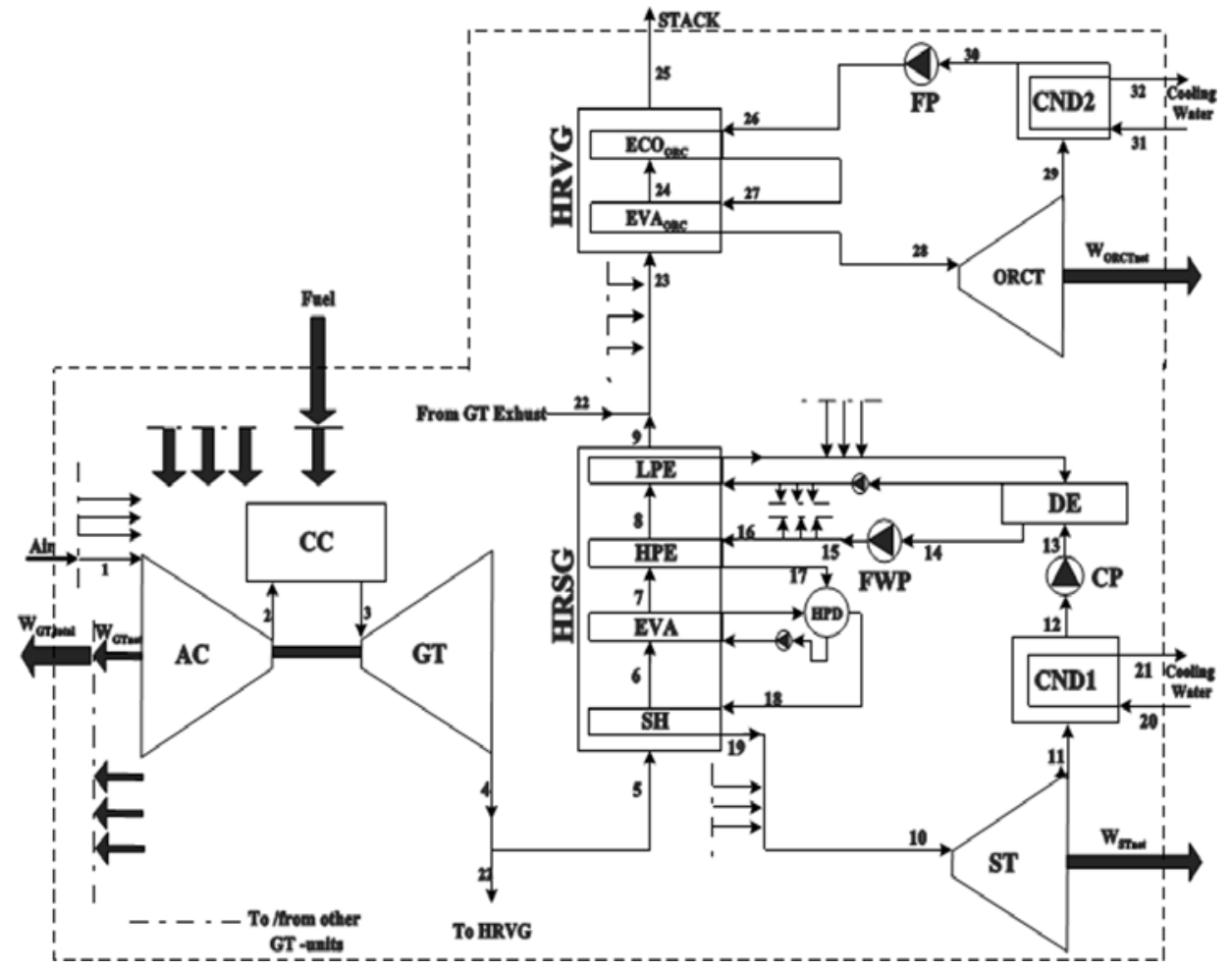

FIG. 1. SCHEMATIC DIAGRAM OF THE MODIFIED SYSTEM UNDER STUDY

Mehran University Research Journal of Engineering \& Technology, Volume 36, No. 1, January, 2017 [p-ISSN: 0254-7821, e-ISSN: 2413-7219] 
By Equations (1-11), the thermodynamic model equation for each equipment of the plant is given in Table 1.

The following assumptions are considered in solving the Equations (12-27).

- $\quad$ Steady state condition prevails in all components of the system.

- $\quad$ Changes in kinetic energy and potential energy of the fluids are neglected.
- $\quad$ Dead- state condition is $1 \mathrm{~atm}$ and $298 \mathrm{~K}$.

- $\quad$ Pressure drop in the combustion chamber is 5\%.

- $\quad$ Heat loss in the combustion chamber, HRSG, and HRVG is $2 \%$.

- $\quad$ The temperature difference in GT exhaust and the main steam is $30 \mathrm{~K}$.

- In HRSG and HRVG, the PPD is $20 \mathrm{~K}$, and APD is $10 \mathrm{~K}$ for the base case.

TABLE 1. MODEL EQUATIONS FOR DIFFERENT DEVICES OF THE PLANT

\begin{tabular}{|c|c|c|}
\hline Device & Equations & \\
\hline Air Compressor & $\dot{\mathrm{W}}_{\mathrm{AC}}=\dot{\mathrm{m}}_{\mathrm{air}}\left(\mathrm{h}_{2}-\mathrm{h}_{1}\right)$ & (12) \\
\hline Combustion Chamber & $\frac{(\mathrm{LHVM})_{\mathrm{f}}}{\lambda} \mathrm{HL}_{\mathrm{CC}}=\sum \dot{\mathrm{N}}_{\mathrm{r}}\left(\overline{\mathrm{h}}_{\mathrm{f}}^{\mathrm{O}}+\overline{\mathrm{h}}-\overline{\mathrm{h}}^{\mathrm{O}}\right)_{\mathrm{r}}-\sum \dot{\mathrm{N}}_{\mathrm{p}}\left(\overline{\mathrm{h}}_{\mathrm{f}}^{\mathrm{O}}+\overline{\mathrm{h}}-\overline{\mathrm{h}}^{\mathrm{O}}\right)_{\mathrm{p}}$ & (13) \\
\hline Gas Turbine & $\dot{W}_{G T}=\dot{m}_{g}\left(h_{3}-h_{4}\right)$ & (14) \\
\hline Steam Turbine & $\dot{W}_{S T}=\dot{m}_{s}\left(h_{10}-h_{11}\right)$ & (15) \\
\hline ORC Turbine & $\dot{W}_{\text {RRC }}=\dot{m}_{\text {orc }}\left(h_{28}-h_{29}\right)$ & $(16)$ \\
\hline \multirow{4}{*}{ HRSG } & SH: $\frac{\dot{m}_{s}}{4}\left(h_{19}-h_{18}\right)=\dot{m}_{g}(1-\psi)\left(h_{5}-h_{6}\right)\left(1-\mathrm{HL}_{H R S G}\right)$ & (17) \\
\hline & Eva: $\frac{\dot{m}_{s}}{4}\left(h_{18}-h_{17}\right)=\dot{m}_{g}(1-\psi)\left(h_{6}-h_{7}\right)\left(1-\mathrm{HL}_{\mathrm{HRSG}}\right)$ & (18) \\
\hline & HPE: $\frac{\dot{m}_{\mathrm{s}}}{4}\left(h_{17}-h_{16}\right)=\dot{m}_{g}(1-\psi)\left(h_{7}-h_{8}\right)\left(1-H L_{H R S G}\right)$ & (19) \\
\hline & HPE: $\frac{\dot{m}_{s}}{4}\left(h_{17}-h_{16}\right)=\dot{m}_{g}(1-\psi)\left(h_{7}-h_{8}\right)\left(1-H L_{H R S G}\right)$ & (20) \\
\hline \multirow[t]{2}{*}{ HRVG } & Eco: $\dot{m}_{\text {orc }}\left(h_{27}-h_{26}\right)=4 \times \dot{m}_{g}\left(h_{24}-h_{25}\right)\left(1-H L_{H R V G}\right)$ & (21) \\
\hline & Eva: $\dot{m}_{\text {orc }}\left(h_{28}-h_{27}\right)=4 \times \dot{m}_{g}\left(h_{23}-h_{24}\right)\left(1-\mathrm{HL}_{\mathrm{HRVG}}\right)$ & (22) \\
\hline Feed Water Pump & $\dot{W}_{\text {FWP }}=\dot{m}_{s}\left(h_{15}-h_{14}\right)$ & (23) \\
\hline Condenser Pump & $\dot{w}_{C P}=\dot{m}_{s}\left(h_{13}-h_{12}\right)$ & (24) \\
\hline ORC Feed Pump & $\dot{\mathrm{W}}_{\mathrm{ORC}}=\dot{\mathrm{m}}_{\mathrm{Orc}}\left(\mathrm{h}_{28}-\mathrm{h}_{29}\right)$ & (25) \\
\hline Steam Condenser & $\dot{m}_{\mathrm{s}}\left(\mathrm{h}_{11}-\mathrm{h}_{12}\right)=\dot{\mathrm{m}}_{\mathrm{CND}}\left(\mathrm{h}_{21}-\mathrm{h}_{20}\right)$ & (26) \\
\hline ORC Condenser & $\dot{m}_{\text {orc }}\left(h_{29}-h_{20}\right)=\dot{m}_{C N D 2}\left(h_{32}-h_{31}\right)$ & (27) \\
\hline
\end{tabular}


- $\quad$ The cooling temperature difference is $15 \mathrm{~K}$ in both condensers.

\section{MODEL VALIDATION}

The simulated results of the model are compared with previously published work for the purpose of model validation. For existing CCPP, the values of the FAR (Fuelto-Air Ratio) and temperature at the different location of HRSG are matched with actual and simulated values available in the published work of the Memon et. al. [3] and illustrated in Fig. 2. While Fig. 3 demonstrate the comparison between simulated values of turbine work and experimental values of previous work [21]. In present work, the source for ORC is exhaust gasses while in published work [21] hot water is used. Therefore, initially, hot water temperature variation was converted into heat input and then at the same heat input, turbine work is

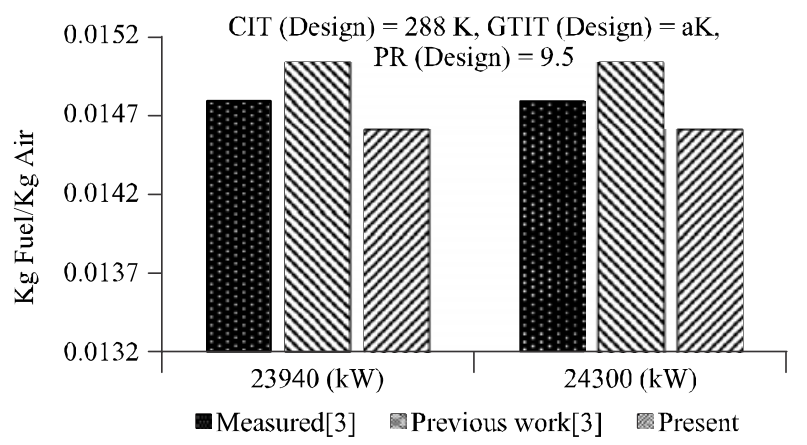

a) FUEL-TO-AIR RATIO AT DESIGN CONDITION

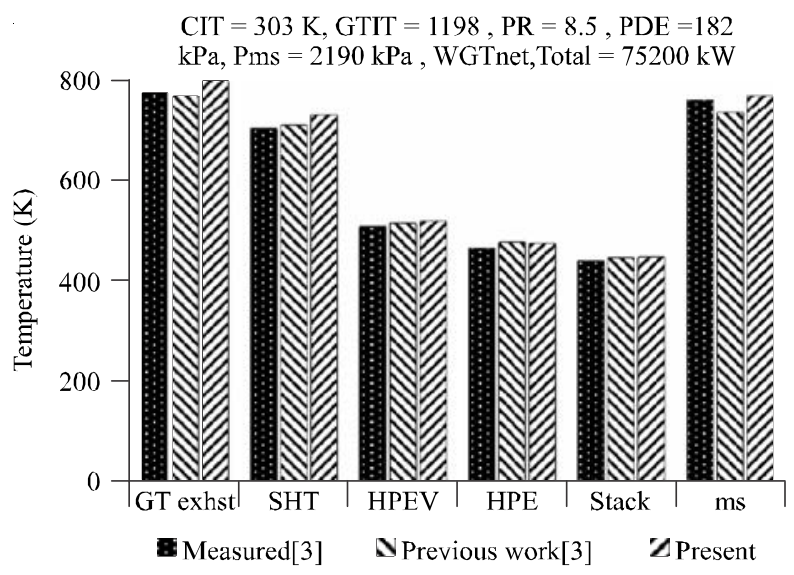

(b) TEMPERATURE OF COMBUSTION GASSES AT DIFFERENT LOCATIONS IN HRSG AND MAIN STEAM TEMPERATURE

FIG. 2. CCPP MODEL VALIDATION simulated and compared with the data. Moreover, it is noted that average difference between experimental and simulated values of turbine work is $2.73 \%$. The comparison of results shows that the simulated values of FAR deviates by $1.22 \%$ from measured values and $2.83 \%$ from previously simulated values, as shown in Fig. 2(a). Similarly, Fig. 2(b) exhibits $2.34 \%$ average differences between simulated and measured values of temperature, whereas simulated results of current and previous work show the difference of $2.19 \%$.

\section{RESULTS AND DISCUSSION}

Fig. 4 demonstrates the variation of ORC net power and stack temperature with a change in OTIP and $\psi$. It is observed that the net power output of ORC increases initially then starts to decline while the stack temperature continuously rises with an increase in OTIP for a given value of $\psi$. For a given value of OTIP, ORC net power output increases, and stack temperature decreases with an increase in $\psi$ due to the generation of a greater mass flow rate of the fluid by HRVG. The ORC net power reaches a maximum of 1250,1500 , and $2250 \mathrm{kPa}$ at bypass fraction $(\Psi)$ of $0,0.05$ and 0.1 , respectively. The increment in OTIP leads to an increase in the enthalpy drop through the turbine and also a reduction in the mass flow rate of fluid generated by HRVG. The initial rise in ORC net power output is due to larger enthalpy drop and the effect of reducing flow rate gradually surpasses it, which causes a decrease in the ORC net power output. The reason for a continuous rise in the stack temperature is the decline in the heat recovery in the economizer due to lower mass flow rate.

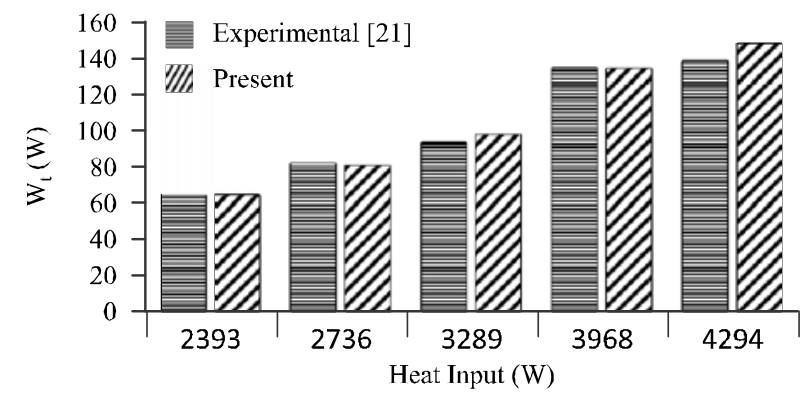

FIG. 3. ORC MODEL VERIFICATION, COMPARING TURBINE WORK AT VARIOUS HEAT INPUTS

Mehran University Research Journal of Engineering \& Technology, Volume 36, No. 1, January, 2017 [p-ISSN: 0254-7821, e-ISSN: 2413-7219] 
The effect of OTIP and $\psi$ on the overall power output and enhancement in efficiency due to integrated ORC is given in Fig. 5. The overall power output of the plant increases as OTIP increases by the amount equal to the additional power produced by the ORC. While an increase in $\psi$ causes a decrease in the overall power output up to OTIP $=2500 \mathrm{kPa}$. That means, at this value the overall power output of the system for all values of $\psi$ is same. This variation is because of as $\psi$ increases the mass flow rate of GT-exhaust through HRSG of the CCPP decreases, which results in a decrement of ST-power output. The diminution in ST-power output remains prominent to the additional ORC net power output up to the given OTIP values, which is surpassed by the latter afterward. At given value of $\psi$, the increment in efficiency due to ORC is observed to be initially increasing then decline with a rise in OTIP.

Fig. 6 exhibits the influence of OTIP and $\psi$ on the overall energy efficiency. For given value of $\psi$, the overall energy efficiency initially rises and then decline with an increase in OTIP. This variation is because initially, the specific fuel consumption decreases and then it increased. Furthermore, specific fuel consumption increases with a

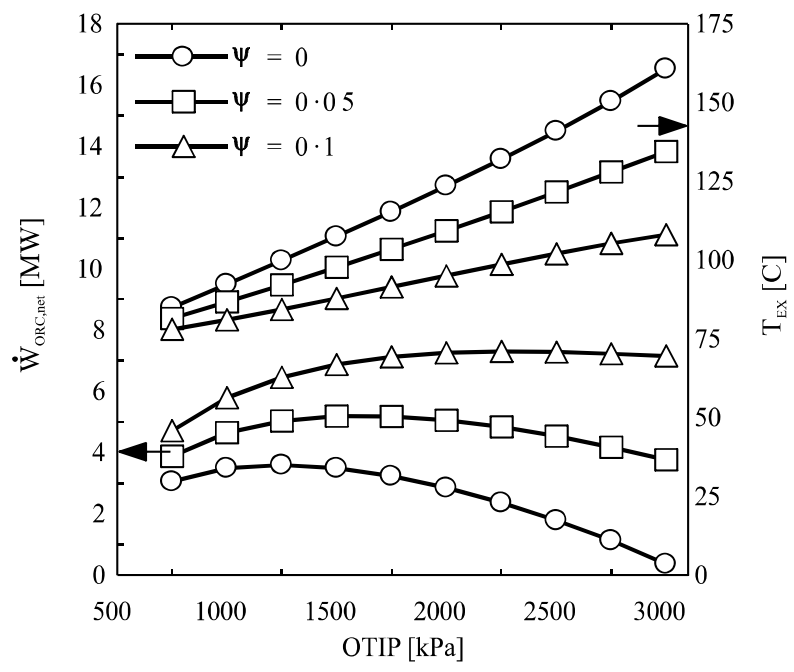

FIG. 4. ORC NET POWER OUTPUT AND STACK TEMPERATURE AS FUNCTION OF OTIP AND $\Psi$ rise in $\psi$ due to decrement in ST power output till OTIP $\leq$ 2500 while as OTIP exceed given value, the enhancement in ORC net power suppressed the decrement in ST power production and specific fuel consumption is decreased. Due to the reason mentioned above, the overall energy efficiency decreases with a rise in $\psi$ till OTIP $\leq 2500 \mathrm{kPa}$ afterward it increases. The maximum overall energy efficiency of $42.58 \%$ is achieved at OTIP $=1250 \mathrm{kPa}$ and $\psi=0$.

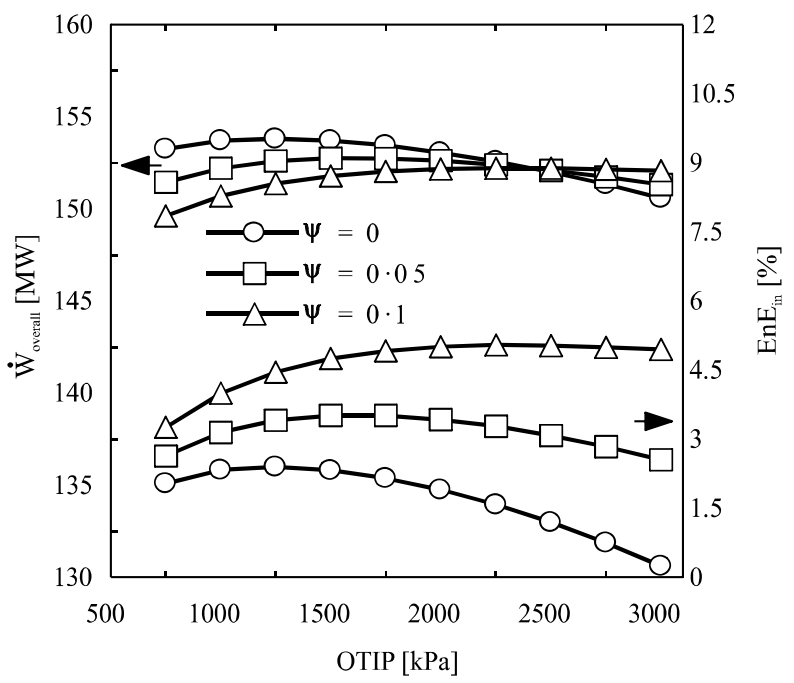

FIG. 5. OVERALL POWER OUTPUT AND EFFICIENCY INCREMENT AS FUNCTION OF OTIP ANDY

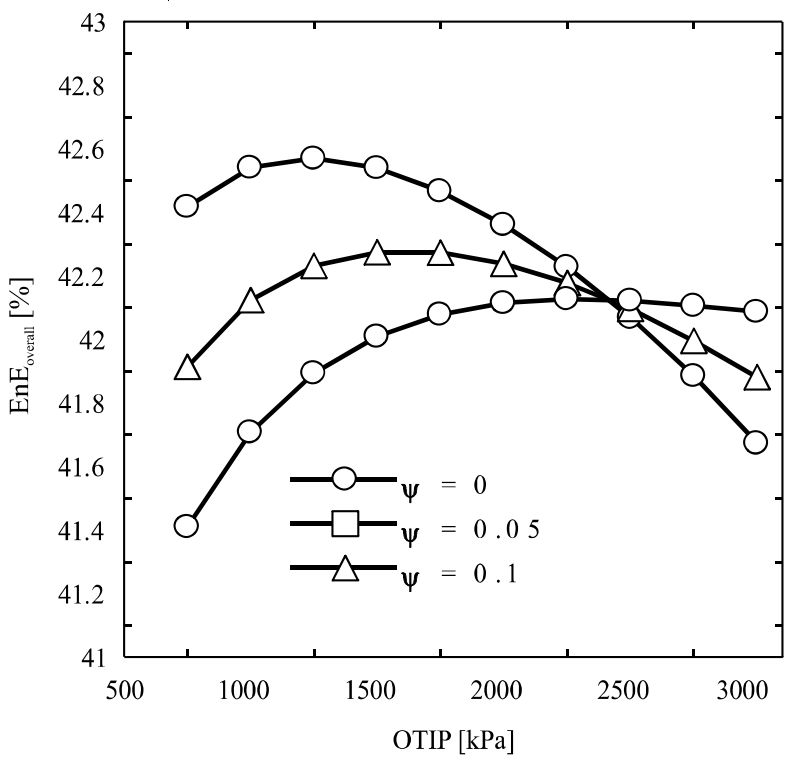

FIG. 6. OVERALL EFFICIENCY OF THE SYSTEM AS A FUNCTION OF OTIP AND $\Psi$

Mehran University Research Journal of Engineering \& Technology, Volume 36, No. 1, January, 2017 [p-ISSN: 0254-7821, e-ISSN: 2413-7219] 
Fig. 7 demonstrates the variation in ORC net power and stack temperature with variation in $\mathrm{APD}_{\text {orc }}$ and $\mathrm{PPD}_{\text {orc }}$. It is observed that net power output of ORC for R245fa decreases while stack temperature increases with a rise in $\mathrm{PPD}_{\text {orc }}$ for a given value of $\mathrm{APD}_{\text {orc }}$. The increase in $\mathrm{PPD}_{\text {orc }}$ leads to lower heat recovery at evaporator that causes reduced mass flow generated in HRVG and net power output of ORC reduces. The reduced mass flow rate generated in HRVG causes to recover lower heat in economizer, which causes an increase in stack temperature. For a given value of $\mathrm{PPD}_{\text {orc }}$, ORC net power output decreases and stack temperature increases with a rise in $\mathrm{APD}_{\text {orc }}$ due to the generation of the lower mass flow rate of fluid in HRVG. The temperature of R245fa at the inlet of evaporator declines with an increase in $\mathrm{APD}_{\text {ore }}$, which causes a reduction in mass flow generated in HRVG.

The influence of $\mathrm{PPD}_{\text {orc }}$ and $\mathrm{APD}_{\text {orc }}$ on the overall power output and enhancement in efficiency due to the modification is shown in Fig. 8. The overall power output and enhancement in efficiency of the system with R245fa decreases with a rise in $\mathrm{PPD}_{\text {orc }}$ and $\mathrm{APD}_{\text {orc }}$ due to the decrement in net power output of ORC. The overall power output is maximum when $\mathrm{PPD}_{\text {orc }}$ and $\mathrm{APD}_{\text {orc }}$ are $7.5 \mathrm{~K}$ and where its value is $154.5 \mathrm{MW}$.

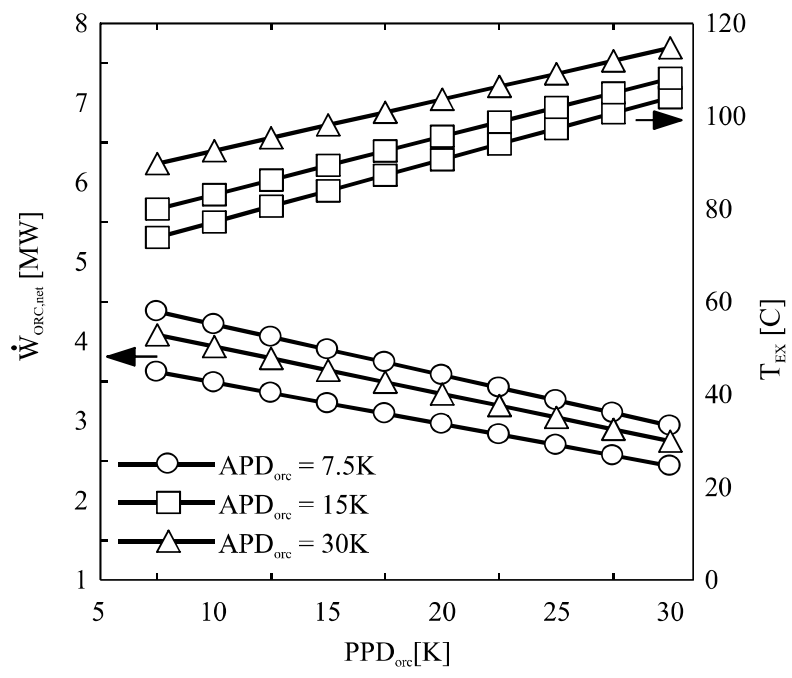

FIG. 7. ORC NET POWER OUTPUT AND STACK TEMPERATURE AS FUNCTION OF PPD ORC AND APD ${ }_{\text {ORC }}$
Lastly, the impact of the $\mathrm{PPD}_{\text {orc }}$ and $\mathrm{APD}_{\text {orc }}$ on the overall efficiency of the system is shown in Fig. 9. It is concluded that overall energy efficiency declines with a rise in $\mathrm{PPD}_{\text {orc }}$ at a given value of $\mathrm{APD}_{\text {orc }}$ due to increasing in specific fuel consumption. Further, the overall efficiency inversely related to $\mathrm{APD}_{\text {orc }}$ for given value of $\mathrm{PPD}_{\text {orc }}$. The maximum overall efficiency of $42.8 \%$ is observed when both $\mathrm{PPD}_{\text {orc }}$ and $\mathrm{APD}_{\text {orc }}$ are $7.5 \mathrm{~K}$.

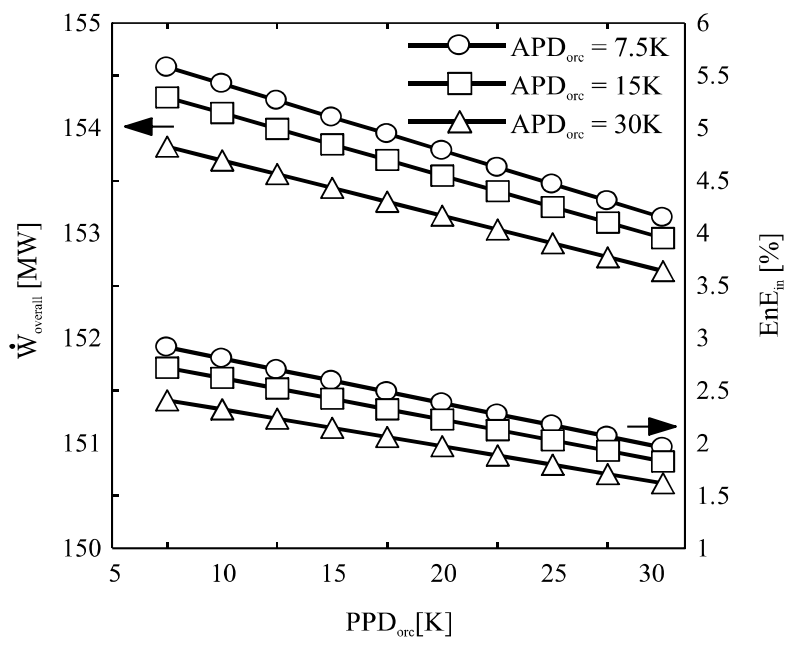

FIG. 8. OVERALL POWER OUTPUT AND EFFICIENCY INCREMENT AS FUNCTION OF PPD ${ }_{\text {ORC }}$ AND APD ${ }_{\text {ORC }}$

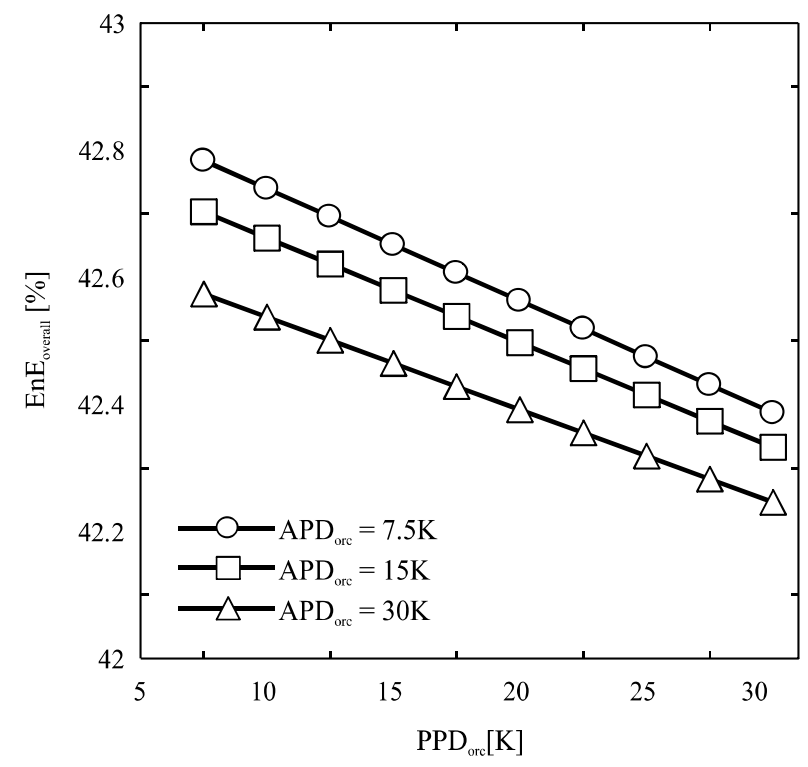

FIG. 9. OVERALL ENERGY EFFICIENCY AS FUNCTION OF $P P D_{O R C} A N D A P D_{O R C}$

Mehran University Research Journal of Engineering \& Technology, Volume 36, No. 1, January, 2017 [p-ISSN: 0254-7821, e-ISSN: 2413-7219] 


\section{CONCLUSION}

In this work, the existing CCPP has been modified with an integrated ORC. The results of the modified model have been compared and analyzed. Initially, a complete thermodynamic model of modified CCPP was developed in EES software and then validated. Then, parametric analysis of the modified CCPP has been carried out to show the influence of operating parameters such as OTIP, $\Psi, \mathrm{APD}_{\text {orc }}$ and $\mathrm{PPD}_{\text {orc }}$ on the performance of the system. The organic fluid R245fa has been selected as the working fluid for the ORC. The results show that selected operating parameters have a significant influence on the various performance parameters. For given value of $\Psi$, the ORC net power increases with OTIP up to certain values afterward it decreases, which causes similar behavior in the overall power output and overall efficiency. The increment in $\Psi$ leads to rising in ORC net power output but decrement in overall power output due to a decrease in ST power output till OTIP $\leq 2500 \mathrm{kPa}$. While the enhancement in ORC net power suppressed the latter and overall power output increases with a rise in $\Psi$ with OTIP beyond given limit value. The stack temperature increased with OTIP and decreased with $\Psi$. Furthermore, ORC net power, overall power output, and enhancement in efficiency decreased with a rise in $\mathrm{PPD}_{\text {orc }}$ and $\mathrm{APD}_{\text {orc }}$, whereas the stack temperature increased with $\mathrm{PPD}_{\text {orc }}$ and $\mathrm{APD}_{\text {orc }}$. The results of this study attributed that ORC is a competitive option for the improvement of efficiency of the power plants in Pakistan. As future work, the economic analysis should be carried out to assess the financial feasibility of ORC.

\section{NOMENCLATURE \\ EnE energy efficiency (\%) \\ $\mathrm{H} \quad$ specific enthalpy $(\mathrm{kJ} / \mathrm{kg})$ \\ $\overline{\mathrm{h}} \quad$ molar specific enthalpy $(\mathrm{kJ} / \mathrm{kmol})$ \\ M molar mass $(\mathrm{kg} / \mathrm{kmol})$ \\ $\dot{\mathrm{m}} \quad$ mass flow rate $(\mathrm{kg} / \mathrm{sec})$ \\ $\dot{\mathrm{N}} \quad$ molar flow rate $(\mathrm{kmol} / \mathrm{sec})$ \\ $\mathrm{P} \quad$ pressure (kpa) \\ $\dot{\mathrm{Q}}$ heat transfer rate $(\mathrm{kW})$ \\ $\mathrm{T}$ temperature $(\mathrm{k})$ \\ $\dot{\mathrm{W}} \quad$ power $(\mathrm{kW})$ \\ LHV lower heating value $(\mathrm{kJ} / \mathrm{kg})$}

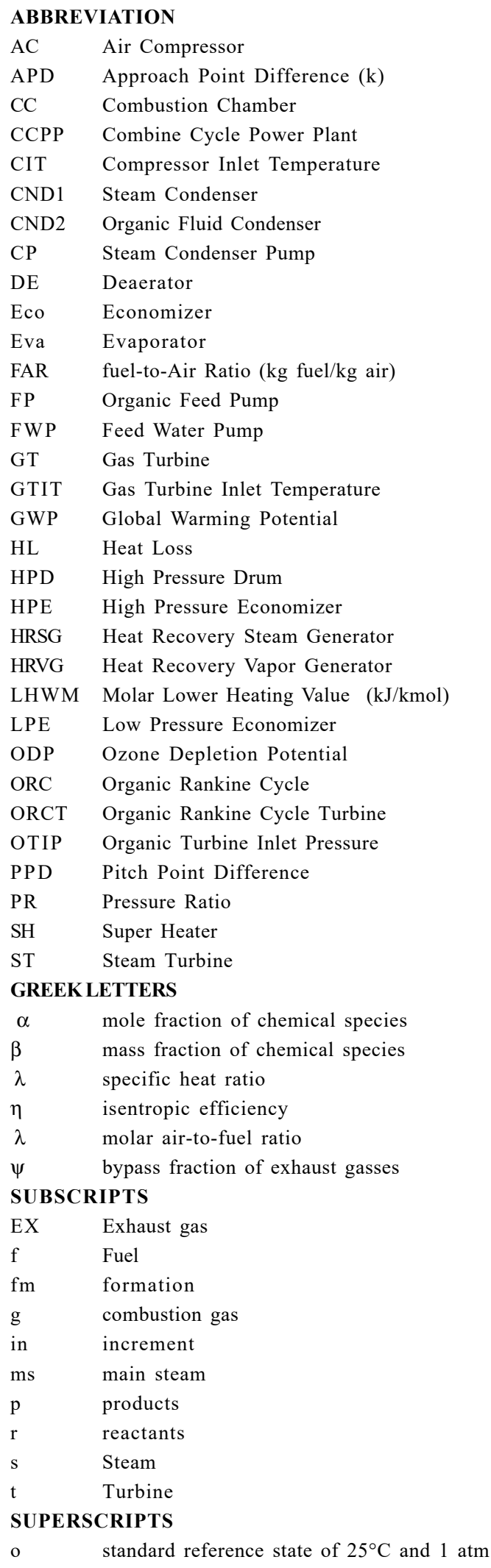




\section{ACKNOWLEDGEMENTS}

The authors gratefully acknowledge the authorities of Mehran University of Engineering \& Technology, Jamshoro, and NED University of Engineering \& Technology, Karachi, Pakistan, for their support to carry out the current work.

\section{REFERENCES}

[1] NEPRA, "State of Industry Report", National Electric Power Regulatory Authority, Islamabad, 2014.

[2] Memon, A.G., Memon, R.A., and Harijan, K., "Thermodynamic Analysis of Simple Gas Turbine Cycle with Multiple Regression Modelling and Optimization", Mehran University Research Journal of Engineering \& Technology, Volume 33, pp. 294-303, Jamshoro, Pakistan, 2014.

[3] Memon, A.G., Memon, R.A., Harijan, K., and Uqaili, M.A., "Parametric Based Thermo-Environmental and Exergoeconomic Analyses of a Combined Cycle Power Plant with Regression Analysis and Optimization", Energy Conversion and Management, Volume 92, pp. 19-35, 2015.

[4] Matsuda, K., "Low Heat Power Generation System", Applied Thermal Engineering, Volume 70, pp. 1056-1061, 2014.

[5] Yogi, G.D., "Solar Thermal Power Technology: Present Status and Ideas for the Future", Energy Sources, Volume 20, pp. 137-145, 1998/02/01 1998.

[6] Peng, S., Hong, H., Jin, H., and Wang, Z., "An Integrated Solar Thermal Power System using Intercooled Gas Turbine and Kalina Cycle", Energy, Volume 44, pp. $732-740,2012$.

[7] Zamfirescu, C., and Dincer, I., "Thermodynamic Analysis of a Novel Ammonia-Water Trilateral Rankine Cycle", Thermochimica Acta, Volume 477, pp. 7-15, 2008.
Tchanche, B.F., Lambrinos, G., Frangoudakis, A., and Papadakis, G., "Low-Grade Heat Conversion into Power using Organic Rankine Cycles - A Review of Various Applications", Renewable and Sustainable Energy Reviews, Volume 15, pp. 3963-3979, 2011.

[10] Wang, L., Roskilly, A.P., and Wang, R., "Solar Powered Cascading Cogeneration Cycle with ORC and Adsorption Technology for Electricity and Refrigeration”, Heat Transfer Engineering, Volume 35, pp. 1028-1034, 2014.

Algieri, A., and Morrone, P., "Energetic Analysis of Biomass-Fired ORC Systems for Micro-Scale Combined Heat and Power (CHP) Generation. A Possible Application to the Italian Residential Sector", Applied Thermal Engineering, Volume 71, pp. 751-759, 2014.

[12] Guo, C., Du, X., Yang, L., and Yang, Y., "Organic Rankine Cycle for Power Recovery of Exhaust Flue Gas", Applied Thermal Engineering, Volume 75, pp. 135-144, 2015.

[13] Peris, B., Navarro-Esbrí, J., Molés, F., and Mota-Babiloni, A., "Experimental Study of an ORC (Organic Rankine Cycle) for Low Grade Waste Heat Recovery in a Ceramic Industry", Energy, Volume 85, pp. 534-542, 2015.

[14] Chacartegui, R., Sánchez, D., Muñoz, J.M., and Sánchez, T., "Alternative ORC Bottoming Cycles FOR Combined Cycle Power Plants", Applied Energy, Volume 86, pp. 2162-2170, 2009.

[15] Valerie, E.P.R., Adesola, O., Yuyao, W., and Al Alili, A., "Waste Heat Recovery from Gas Turbine Flue Gases for Power Generation Enhancement in a Process Plant", International Journal of Thermal \& Environmental Engineering, Volume 12, pp. 53-60, 2016.

[16] Baral, S., Kim, D., Yun, E., and Kim, K., "Energy, Exergy and Performance Analysis of Small-Scale Organic Rankine Cycle Systems for Electrical Power Generation Applicable in Rural Areas of Developing Countries", Energies, Volume 8, pp. 684-713, 2015.

[17] Algieri, A., and Morrone, P., "Comparative Energetic Analysis of High-Temperature Subcritical and Transcritical Organic Rankine Cycle (ORC): A Biomass Application in the Sibari District", Applied Thermal Engineering, Volume 36, pp. 236-244, 2012. 
[18] Abadi, M.J., Hooshmand, P., Khezri, B., and Reza, A., "Investigation of Using Different Fluids for Using in Gas Turbine-Rankine Cycle", Indian Journal of Science Reserch, Volume 1, pp. 74-81, 2014.

[19] Juhasz, J.R., and Simoni, L.D., "A Review of Potential Working Fluids for Low Temperature Organic Rankine Cycles in Waste Heat Recovery", $3^{\text {rd }}$ International Seminar on ORC Power Systems, Brussels, Belgium, 2015.
[20] He, S., Chang, H., Zhang, X., Shu, S., and Duan, C., "Working Fluid Selection for an Organic Rankine Cycle Utilizing High and Low Temperature Energy of an LNG Engine", Applied Thermal Engineering, Volume 90, pp. 579-589, 2015.

[21] Farrokhi, M., Noie, S.H., and Akbarzadeh, A.A., "Preliminary Experimental Investigation of a Natural Gas-Fired ORC-Based Micro-CHP System for Residential Buildings", Applied Thermal Engineering, Volume 69, pp. 221-229, 2014. 